\title{
Pseudoglandular Squamous Cell
}

\section{Carcinoma}

National Cancer Institute

\section{Source}

National Cancer Institute. Pseudoglandular Squamous Cell Carcinoma. NCI Thesaurus.

Code C4106.

A squamous cell carcinoma characterized by the formation of gland-like structures. 